\title{
The mystery of the mouse $\alpha$-globin pseudogene
}

from R.A. Flavell

THE chromosomes of multicellular organisms seem to be full of a wide variety of DNA sequences which are of no apparent use to their hosts. Some of these sequences, termed pseudogenes, are defective copies of functional genes. The laboratory mouse has two such crippled genes - the $\alpha$-globin pseudogenes. However, one of them, $\alpha \psi 3$, is different from other pseudogenes described to date. It has precisely (to the nucleotide) lost the intervening sequences (or introns) which are present in the functional a-globin genes $^{1,2}$. It is not known why introns are commonly found in the genes of vertebrates - they are removed from the primary RNA transcript during production of a functional messenger RNA and it seems a complicated method of encoding genetic information when intronless genes work well in prokaryotes (for speculations on this subject see ref.3). But whatever the reasons why the insertions are present in the normal $\alpha$-globin genes; the question of how $\alpha \psi 3$ lost its introns is a riddle of great interest.

One possible origin of $\alpha \psi 3$ is that an intronless $\alpha$-globin mRNA altered a duplicated normal $\alpha$-globin gene to an exact copy of itself by gene conversion ${ }^{1}$. However, although gene conversion between homologous DNA sequences is well characterized, gene conversion by a RNA has not been seen. Another, perhaps more plausible possibility is that $\alpha \psi 3$ somehow derived from the copying of an $\alpha$-globin mRNA into a DNA molecule by the retrovirus-encoded enzyme reverse transcriptase. Such a DNA might also alter a duplicate $\alpha$-globin gene by gene conversion.

The most exciting proposal is, however, that an $\alpha$-globin mRNA actually became incorporated into the RNA genome of a retrovirus. Retroviruses are equally at home as either RNA-containing viruses or DNA copies of this RNA (called proviruses) which are integrated into the host cell DNA. Therefore, provided that one accepts that an $\alpha$-globin mRNA could gain entry into the retrovirus genome, it is only necessary to invoke the normal infectious cycle of the virus to explain the presence of $\alpha \psi 3$. Retroviruses are certainly capable of incorporating cellular genes into their RNA genomes ${ }^{4}$ and, significantly, comparisons between the cellular and viral genes show that the RNA copies of these cellular genes have sometimes lost the introns which characterize the parent genes ${ }^{5}$. So far the only genes known to have been 'captured' by a retrovirus are those conferring an easily scored phenotype on infected cells (tumorigenic

R.A. Flavell is at the Imperial Cancer Research Fund Laboratories, Burton Hole Lane, London NW7 IAD. transformation), but it is reasonable to suppose that a retrovirus might incorporate any piece of the cells' transcribed DNA, such as the $\alpha$-globin gene. Of course, such an event would have to occur in the germ line of the mouse to survive the eventual death of its host.

Such a model demands that the newly integrated $\alpha$-globin gene be accompanied by a retrovirus provirus. In this issue of Nature (p.426), Lueders et al. describe their analysis of the flanking DNA of both $\alpha$-globin pseudogenes and the $\alpha$-globin genes of mouse. They show that $\alpha \psi 3$ is indeed flanked by a pair of retrovirus-like elements whereas the other $\alpha$-globin genes are not. The elements, which are present in about 1,000 copies per mouse genome, encode a class of virus-like entities called intracisternal type A particles (IAPs) which share close similarities with the commonly studied type $B$ and type $C$ retroviruses. Unfortunately, it is by no means clear whether IAP elements are responsible for the creation of $\alpha \psi 3$, as the pseudogene is flanked on either side by about 4 kilobases of cellular DNA before the IAP elements are reached, whereas the model demands that $\alpha \psi 3$ be actually connected to the retroviral sequences. It is at this point that the real problem in determining the origin of this pseudogene raises its head.

The pseudogene emerged roughly 20 million years ago, since when there may have been numerous alterations to the gene and its immediate environment, perhaps because $\alpha \psi 3$ was probably superfluous to the metabolic requirements of its host. Deletion or insertion of other DNA sequences may have masked its original configuration. The authors point out that a way around this problem may be to study the same pseudogene in related mouse species and in the rat. By looking for alterations which have cropped up during the evolution of these species, the original configuration of $\alpha \psi 3$ may be revealed. Two of the authors are accumulating more data on mouse genes flanked by other IAP elements which should show whether the $\alpha \psi 3-$ IAP complex is particularly unusual. Doubtless, the sequences between the pseudogene and the IAP elements are also being scrutinized for clues to the origin of the arrangement.

If IAPs do turn out to have a role in the creation of the $\alpha$-globin pseudogene, could such a phenomenon affect genome evolution by inducing the migration of functional DNA sequences to new sites? Or are we looking at a way of creating merely new 'junk' DNA?

\footnotetext{
1. Nishioka, Y., Leder, A. \& Leder, P. Proc. natn. Acad. Sci. U.S.A. 77,2806 (1980).

2. Vanin, E.F., Goldberg, G.I., Tucker, P.W. \& Smithies, O. Nature 286, 222 (1980).

3. Gilbert, W. Nature 271, 501 (1978)

4. Bishop, J.M. Cell 23, 5 (1981)

5. Goff, S.P., Gilboa, E., Witte, O.N. \& Baltimore, D. Cell 22, 777 (1980)
}

\section{0 years ago}

\section{THE INDIAN DARTER}

The Darters form a very peculiar type of birds of the order Steganopodes, allied to the Cormorants in structure, but very Heron-like in gait and gesture. The Darter in its normal position sits erect upon a branch or stump overlooking the water. When proceeding to fish it dives head foremost into the stream, and swimming entirely under water, transfixes its

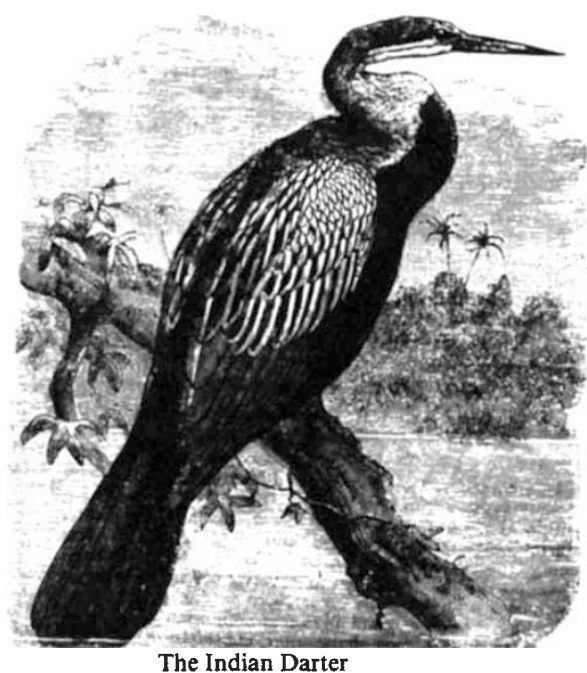

finny prey with the rapidity of lightning. Emerging from the water with the fish speared upon its long slender beak, the Darter chucks the fish into the air, and catching it head foremost with unerring aim, swallows it whole.

The Darters usually exhibited in the Royal Society's Gardens are of the South American species (Plotus anhinga), but in 1878 an example of the African form Le Vaillant's Darter (Plotus levaillanti) ${ }^{1}$ was received. In April last an example of a third species of this genus - the Indian Darter (Plotus melangaster) was obtained in exchange from the Zoological Gardens of Calcutta.

"In a state of nature," as Dr. Jerden tells us, "this beautiful diver is found throughout all India, Ceylon, Burmah, and Malayana. It is exceedingly numerous in some parts of the country, especially in Bengal; hundreds are often to be seen on a single jheel. They hunt singly in general, or in scattered parties, but often roost in company, both at night and in the middle of the day, when numbers may be seen perched on the trees overhanging some tank or river. They float low on the water, often with nothing but the head and neck visible, and swim and dive with rapidity. After feeding for some time they perch on the bough of a tree or on a pole or stone, and spread their wings out to dry as the Cormorants do." From Nature 25, 24 January, 297, 1882. 